\title{
방재교육을 위한 실천공동체로써 전통향약의 활용과 시사점 The Application of Hyangyak Based on Communities of Practice for Disaster Prevention Education and Its Implications
}

\author{
최준호* · 최충익** \\ Choi, Junho*, and Choi, Choongik ${ }^{* *}$
}

\begin{abstract}
This article attempts to explore some strategies for community-friendly disaster prevention education based on the traditional Korean community of practice, Hyangyak. This paper also employed Hyangyak as a methodological research framework. We found that Hyangyak would be able to play a critical role in tackling disaster prevention education. The results suggest that the concept of community of practice is compatible not only theoretically but also ideologically with Hyangyak. It is also found that the Hyangyak covenant among citizens has provided the public with details of disaster prevention education, which include citizen participation, disaster management, and organization operation. This study's findings illustrate such things as the development of an autonomous self-help spirit by community members, voluntary participation, dissemination of community concerns, and co-learning that reflects community circumstances.
\end{abstract}

Key words : Hyangyak, Disaster Prevention Education, Community of Practice, Participatory Approach

\section{요 지}

최근 사회가 복잡해지고 재난발생의 불확실성이 증가함에 따라 실천공동체의 개념을 활용한 방재교육이 주목을 받고 있다. 본 연구에서는 이러한 방재교육 구성방안으로써 우리의 공동체 정신에 근간이 되고 있는 전통향약의 개념을 적용한다. 분석결과, 실천공동체는 단지 이론적 개념이 아니라 우리의 전통향약이 추구하는 이상향과 목적을 같이 하고 있음을 확인하였다. 따라서 앞으로의 방재교육은 향약의 정신을 적용하여 ‘지역사회 구성원으로써의 주체적 자조(自助)능력 함양', ‘공동체적 참여를 통한 현안의 공유 및 전파' 그리고 ‘지역사회 실정반영을 위한 상호 배움' 등의 방향성을 가지고 개선되어야 한다.

핵심용어 : 향약, 방재교육, 실천공동체, 참여형 어프로치

\section{1. 서 론}

우리나라의 방재교육은 2014년 세월호 사고이후 점차 개선되고 있으나 아직은 기초단계에 머무르고 있는 실정이 다. 그 내용을 살펴보면 수업일수와 내용적인 측면에서 크게 강화되고 있으나 교사가 학생에게 지식을 전달하고 실습하 던 전통적인 교육패러다임에서 크게 벗어나 있지 않다(J.
Choi and Choi, 2018). 이러한 전문가-비전문자 구도의 일방 적인 방재교육은 재난발생시 유사상황에서 효과를 발휘하 여 방재의식 증가라는 단기간의 목표에 도움이 될 수 있다. 즉, 현재 우리나라의 방재교육은 교육에 참여한 사람의 만족 도나 방재인식의 향상이 일차적인 목표가 되고 있다. 이는 전통적 교육방식의 패러다임을 기반으로 하여 그 목적에 부합한 지식을 학습했는가에 대한 것이 중요한 부분을 차지

*정회원, 강원대학교 행정학과 박사후 연구원(E-mail: smolts80@gmail.com)

Member, Post-DOC, Department of Public administration, Kangwon National University

**교신저자, 정회원, 강원대학교 행정학과 교수(Tel: +82-33-250-6813, Fax: +82-33-259-5606, E-mail: choich@kangwon.ac.kr)

Corresponding Author, Member, Professor, Department of Public administration, Kangwon National University 
한다는 것을 뜻한다. 그러나 보다 거시적인 관점으로 방재교 육의 패러다임을 다시금 생각해야 할 필요가 있다.

앞으로의 방재교육은 전문가가 방재지식을 전달하여 비 전문가에게 숙지시키는 일방적인 교육방식을 넘어서야 한 다. 현대사회에서는 재난 리스크가 불확실하고 복잡하여 상호 연계되어 작용한다(Renn, 2008). 따라서 교육으로 숙지 된 유사상황을 넘어선 재난에 대응할 수 있고, 이를 사전에 대비하는 주체적이며 협력적인 방재태도의 형성 및 함양이 방재교육의 가장 우선적인 목표가 되어야 한다.

방재교육의 한계는 비단 우리나라의 문제일 뿐만 아니라 국제적으로도 지적되고 있다. Yamori and Kao (2007)는 그 방재교육의 문제점을 다음과 같이 정리하였다. 첫째, 방재 전문가의 단순한 방재지식 전달에 중점을 두고 있다는 점, 둘째, 재난의 사회적 취약성(social vulnerability)이 증가 하는 현 상황에서 상호 협력방식이 미흡하다는 점, 셋째, 지속적인 교육효과를 위한 지역사회 전체의 총체적 대응방 식이 결여되었다는 점 등이다.

이러한 상황에서 실천공동체(community of practice) 이론 이 새로운 방재교육 방법론으로써 주목을 받고 있다(Yamori, 2009; Sun et al., 2012; Iwahori et al., 2015). 실천공동체는 Lave and Wenger (1991)가 주창하였는데 Wenger (1998)가 회사와 조직에서의 활동에 관한 이론적인 연구를 수행한 이후, 학교 및 세계적인 기업1)과 조직에서 자발적인 전문성 을 개발하는 지식경영을 위한 전략으로 활용되고 있다(Kim and Lim, 2010).

실천공동체는 공통된 관심사항을 가진 구성원들이 신뢰 를 바탕으로 해당영역의 관련지식 및 기술을 체화하고 이러 한 결과를 공유 및 지속적으로 실천하는 집단 공동체를 말한다(Wenger and snyder, 2000; Wenger et al., 2002). 앞서 말한 방재라는 공통된 관심영역을 위해 관련된 지식과 기술 을 지역사회에서 전방위적으로 체화하고 실천해야 하는 만큼 방재교육에서 실천공동체가 가지는 의의는 매우 크다 고 할 수 있다.

그러나 본 논문에서는 이러한 실천공동체의 개념을 비판 없이 수용하기보다 우리의 역사 속에서 존재하였으며 현재 까지도 우리의 공동체 정신에 영향을 미치고 있는 전통 향약(鄉約)을 통해 적용해보고자 한다. 향약에서 이어왔던 공동체의 정신2)은 오늘날의 실천공동체로서의 방재교육 방안 검토를 위해 시사하는 바가 많을 것이다. 향약은 우리의 정신적 유산으로 영향을 미치고 있으며 현재도 많은 지역에 서 명맥이 지속되고 있는 규약이기 때문이다(Kim, 2009). 더구나 향약은 전쟁과 당파싸움 등으로 혼란했던 상황에서 지역사회의 상호신뢰를 바탕으로 한 협력을 통해 공공선을

1) 제록스, IBM, 쉘(Shell) 등의 지식경영을 위해 활용되었다(Saint-Onge and Wallace, 2003).

2) 한국국학진흥원의 자료분석 결과, 한국인의 대표 문화유전자는 '공동 체와의 자연스러운 어울림'으로 도출되었다(Park, 2014).
유지하려 했던 점을 살펴볼 때 현재 우리가 궁극적으로 추구하는 방재교육의 이상향과 크게 다르지 않다.

방재교육이 효과적이며 지속성을 갖추기 위해서는 지역 사회가 온정적인 공동체 정신을 형성하는 것이 필요하다 (Lee, 2012). 지역사회의 공동체 정신의 발휘는 세계적으로 도 트렌드(UNISDR, 2005, 2015; Choi and Yoon, 2017)가 되어 실천되고 있으며. 이와 관련된 관련 국제적인 연구도 다수 존재한다(Chen et al., 2006; Matuda and Okada, 2006; Bajek et al., 2008; Na et al., 2009; Okada et al., 2013; Samaddar et al., 2015). 우리나라에서도 우리의 지역사회 공동체와 협력에 대한 다수의 선행연구가 진행되었다. 그러 나 방재를 위한 공동체 정신의 함양과 해결방안을 전통적으 로 실존했던 정신적 문화유산에서 찾으려한 시도는 없었다 는 점에서 본 논문의 의의는 매우 크다고 할 수 있다.

이상을 정리하자면, 본 논문은 앞으로의 방재교육을 위해 실천공동체의 개념을 활용하는데 이를 위한 방법론으로써 우리의 전통향약을 활용하고자 한다. 본 논문의 구성은 다음 과 같다. 제 2 장에서는 방재교육에서의 실천공동체의 중요성 을 논의한다. 제 3 장에서는 실천공동체와 향약의 관계를 살 펴보고 전 장에서 도출된 세 가지 핵심요소를 향약의 관점으 로 분석하여 방재교육을 위한 시사점을 살펴본다. 마지막 제4장에서는 이를 요약 및 종합하며 결론을 맺는다.

\section{2. 방재교육과 실천공동체}

\section{1 앞으로의 방재교육 방향}

교육이란 ‘인간이 삶을 영위하는 데 필요한 모든 행위를 가르 치고 배우는 과정이며 수단이다. 교육에 대해 여러 학자들이 정의를 내리고 있지만, 모두 교육을 인간형성의 과정으로 바라보 고 있다. 이러한 인간형성을 위한 과정은 올바르고 바람직한 방향이 되어야 하며, 이는 보다 나은 사회개조를 위한 수단으로 활용되어야 한다(The Academy of Korean Studies, 2018).

따라서 방재교육이란 재난 발생시 적절한 방재활동을 할 수 있는 사람으로 형성하기 위한 필요한 행위를 가르치고 배우는 과정이며 나아가 보다 재난에 강한 사회개조를 위한 수단이라고 정의할 수 있다. 즉, 방재를 위해서는 지역에 맞는 적절한 해결책을 구성원이 협력으로 만드는 것이 중요 하며 이러한 해결책을 이끌어내기 위한 실천방법이 방재교 육이라고 할 수 있다(Shirosita, 2012). 방재교육에서 다루는 사항은 재난피해를 사전에 경감시키고, 재난 발생후에는 수습을 위한 긴급대응활동과 복구활동, 그리고 원거리의 구조활동 등 총체적인 내용이 포함된다.

그러나 대부분의 방재교육에서는 전문가가 지식을 전달 하여 비전문가인 일반인이 활용하는 방식을 주로 실시한다 (Yamori, 2009). 그러나 이는 지역사회의 제 1 차 피해자인 주민의 현안(concern)이 제대로 고려되지 않아 현실성이 부족할 수 있다는 점과 지역외의 타인이라 할 수 있는 
전문가가 마련한 대책을 그대로 수용하는 과정에서 실효성 에 문제가 발생할 수 있다. 즉, 방재교육이 단순히 전문가의 지식을 일반시민에게 일방적으로 전달하는 것으로 인식한 다면 현실성과 적용가능성의 측면에서 문제가 야기될 수 있다(Yamori and Kao, 2007).

방재교육의 목표는 지역사회 구성원 모두가 방재전문가 가 되는 것이 아니다. 전문가는 전문가로서 일반시민은 일반 시민으로서 대등한 입장에서 각자의 능력과 자원을 활용하 여 방재활동에 참여하는 것이 중요하다(Shirosita, 2010). 즉, 각자의 사회경제적인 위치에서 야기되는 부득이한 입장 을 상대방에게 이해시키고, 거기서 나오는 현안(concern)을 상호 공유하여 사회적으로 실현가능한 해결책을 만들어 가는 것이 핵심이다. 이와 더불어 방재교육은 방재에 관심이 적은 시민을 대상으로 하며 이들과 어떻게 접촉할 것인지 참여방안을 구성(design)하는 것도 중요하다(Atsumi, 2006).

\section{2 실천공동체의 개념 및 특징}

전 장에서 상술하였듯이 이러한 상황에서 실천공동체가 앞으로의 방재교육을 위한 새로운 방법론으로 주목을 받고 있다. 실천공동체(community of practice)란 문제해결을 위 해 자발적으로 참여한 구성원들이 상호간 신뢰를 통해 해당 영역의 주제와 목적에 맞는 지식과 기술을 체득하고, 그 결과를 지속적으로 공유하고 실천하는 과정을 통해 지식과 전문성을 보다 깊이 있게 재창출하는 집단공동체를 말한다 (Wenger and synder, 2000). Wenger et al. (2002)는 공동의 관심사항을 공유하고 있는 구성원들이 상호간의 지속적인 교류를 통해 전문성을 갖추고 지식을 심화시키는 사회적인 연대라고 하였다. 이를 정리하면 실천공동체에서 중요한 핵심은 해당주제의 해결을 위해 자발적으로 참여하고3) 상호 간의 신뢰를 바탕으로 정보와 지식을 지속적으로 교류하는 것이라고 할 수 있다.

실천공동체는 가시적 혹은 비가시적일 수도 있고, 의도 적 혹은 자연적일 수 있다. 즉 그 개념은 하나의 유형으로 규정되는 것이 아니고 역동적이라 할 수 있다. 이러한 실천 공동체가 중요한 이유는 개인과 환경, 집단 간의 상호작용 으로 인한 직간접적인 실천을 통해 개별적인 지식 습득과정 으로는 해결할 수 없는 암묵지(tacit knowledge)가 보다 확실하게 학습자의 것으로 체득되고 필요에 따라 형식지 (explicit knowledge)로 외현화되어 행동이라는 실천으로 진행 가능하기 때문이다(Jeon, 2012).

이러한 실천공동체의 구성요소는 영역(domain of knowledge), 공동체(community), 실천의 공유(shared practice) 이 세 가지로 이루어져 있다(Wenger et al., 2002). 이를 정리하면 다음과 같다. 첫째, 영역(domain of knowledge)은 실천공동체가 추구하

3) 실천공동체에서 말하는 참여란 문제해결을 위해 함께 한다는 의미를 넘은 것으로써 해당영역의 공동체 구성원으로 성장하여 정체성을 확 립하는 과정을 말한다(Wenger, 1998).
는 지식의 범위를 나타내며 실천공동체의 정체성(identity) 과 관련된다. 실천공동체가 효과적으로 운영되기 위해서는 영역을 구체화하고, 고착되지 않고 발전할 수 있도록 사전에 설정하는 것이 중요하다. 잘 설정된 영역은 구성원을 결집시 키고 공동체의 목적과 가치를 외부로부터 합법화 받는데 중요한 요소이다. 그리고 이러한 영역 내에서 구성원의 자발 적 참여와 지속적 커뮤니케이션을 통해 공동체의 정체성이 발전해 나갈 수 있다(Wenger, 1998; Choi, 2010).

둘째, 공동체(community)는 사람간의 관계를 의미하는데 일반적인 의미로써 단순히 '사람들의 모임'을 뜻하는 것이 아니라 실천요소와 관여한다. 이 실천요소는 존중과 신뢰를 바탕으로 하는 상호적 관여(mutual engagement), 공통의 관심이자 목적인 공동업무(joint enterprise), 구성원들 간의 실천을 통해 생성되고 공유하는 유·무형의 공동자산(shared repertoire)으로 구성된다 즉, 공동체는 단순히 지식을 공유하 는 모임이 아니라 상호작용을 통해 관계 및 책무성이 형성되 고, 이를 통해 암묵지도 학습되고 공유되는 관계를 말한다 (Wenger, 1998; Kim, 2003; Choi, 2010; Jeon, 2012).

셋째, 실천의 공유는 구성원이 학습하고 공유하는 구체적 지식이며 사회적 맥락(social context)에서 지속적으로 변화 한다(Lave and Wenger, 1991) 즉, 특정한 행동양식, 사고방 식, 집단적 행태 등 구성원이 공유하는 레퍼토리(repertoire) 이다. 실천은 구성원의 상호작용을 지속시키며 재생산되고 이러한 과정을 통해 공동체의 정체성이 형성된다. 즉, 실천의 공유는 공동체를 결집시키는 일종의 문화라고 할 수 있다 (Wenger, 1998; Jeon, 2012).

\section{3 방재교육에 대한 실천공동체의 중요성}

방재교육은 재난의 제 1 차 피해자이자 방재계획의 제 1 차 주체로서 주변과 협력(coordination)하고 자신과 가정을 스 스로 지키는 자주적인 방재능력을 함양하는 데 있다.4) 따라 서 방재교육은 단순히 재난에 대해서 대비해야하는 지식과 방법을 가르치고 전달받는 일방적인 교육이 아니라 상호 소통하는 교육으로써 상호협력과 지역사회 구성원간의 총 체적 대응의식이 함양되어야 한다. 이러한 방재교육으로 지향하기 위해 실천공동체가 가지는 의의는 크다.

실천공동체에서 말하는 교육을 Lave and Wenger (1991) 와 Yamori and Kao (2007)의 연구를 바탕으로 재구성하면 '학습자(배우는 사람)의 내면화(internalization)', 가르치는 사람과 배우는 사람이 참여하는 '실천공동체의 형성', 실천 공동체에 참여하는 사람의 ‘정체성 형성', 이 세 가지 요소가 통합된 것이라고 볼 수 있다. 이는 2.2. 절에서 지적한 실천공 동체의 세 가지 구성요소와 맥락을 같이한다.

이 세 가지 요소를 통해 방재교육에 있어서의 실천공동체의 의의를 살펴보면 다음과 같다(Fig. 1). 첫째, '학습자의 내면화'

4) 재난에 대한 대처에 있어서 행정(국가 및 지자체)에서 수행하는 지원 서비스를 지원받으나 이에 대한 한계를 인식한다는 전제가 수반된다. 
는 우리가 상식적으로 말하는 교육의 의미로써 지식·기술을 모르고 있는 사람(일반인)이 알고 있는 사람(전문가, 행정 공무원 등)으로 부터 학습하는 것을 말한다(Yamori, 2011). 방재교육에서 단순한 방재지식의 일방적 전달은 예상할 수 있고 가시화할 수 있는 재난에 대비할 때 유용하다. 예를 들어 소화기 사용법이라던지, 지진 발생시 우선 책상 밑으로 몸을 피한다던지 등의 요령은 전문가를 통해 전달받으면 화재나 지진발생시 어렵지 않게 적용할 수 있다.

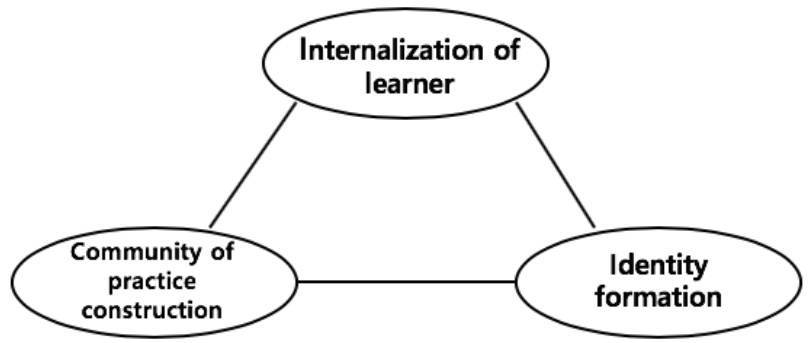

Fig. 1. Three Education Points for Community of Practice (Lave and Wenger, 1991; Yamori and Kao, 2007)

둘째, 가르치는 사람과 배우는 사람의 참여를 통한 '실천 공동체의 구축’은 전문가와 일반인이 함께 참여하는 공동체 를 형성한다는 것이다. 이때의 참여의 개념은 방재지식이 풍부한 전문가이든 부족한 일반인이든 모든 사람들이 각각 다름을 인정하고, 각자 가지고 있는 정체성을 발휘하며 실천 공동체에 전면적으로 참여(full participation)하는 것을 말한 다(Lave and Wenger, 1991; Yamori and Kao, 2007). 이는 첫 번째 요소인 '학습자의 내면화'가 가지고 있는 - 즉, 교육의 협의(狹義)에서 말하는- 한계를 보완하는 요소이다. 즉, 단순히 전문가가 일반인에게 지식을 전달하는 것은 방재 교육의 한 요소일 수 있으나 전부가 아니라는 의미이다. 예를 들면 전문가로부터 방재지식을 전수받은 일반인이 본인만 그것을 알고 그치는 것이 아니라 주변 이웃에게 방재지식을 공유하여 지식이 확대 - 재생산되는 과정이 선 순환되면서 방재를 위한 구성원간의 공동체가 점증적으로 구축이 되고, 이를 통해 참여하는 인적 - 물적자원이 확장되 어 가는 식이다.

셋째, 실천공동체에 참여하는 사람의 '정체성 형성'은 전수받은 지식을 내면화하는 수준이 아니라 정체성이 변화 하는 것이다(Lave and Wenger, 1991). 예를 들어 방재교육 현장에서, 일반인의 정체성은 '(전문가의 지식과 기술등의 전수를 통한) 도움을 받는 사람'에서 '(도움이 필요한 재난약 자를) 도울 수 있는 사람'으로 변화하고 것이고, 전문가는 '자신의 지식 등을 전수하여 일반인을 돕는 사람'에서 '(일반 인에게 지역이 처한 재난 리스크 및 지식5)을 전수받는) 도움을 받는 사람'으로 정체성이 변화하는 것을 말한다

5) local knowledge
(Yamori, 2009). 이러한 정체성의 변화는 궁극적으로 재난관 리 방식의 변화를 야기할 수 있다. 이른바 행정의존의 톱다운 식 접근(Top-down approach)에서 지역사회의 합의형성을 기반으로 하는 더욱 주민참여적인 상향식 접근(A more bottom-up approach)으로 나아가는 촉매제가 될 수 있다.

종합해보면 실천공동체에서 말하는 방재교육의 목표는 일반인이 전문가로부터 일방적으로 방재지식과 기술을 전 수받은 것을 넘어 모처럼 얻은 지식을 주변사람과 공유하고, 이를 통해 방재를 위한 공동체가 구축되어 구성원간의 정체 성 변화와 함께 궁극적으로 안전한 지역사회라는 목표달성 을 위해 지속적으로 실천하는 것이라 할 수 있다.

정리하자면 사회가 발전하고 구조가 복잡해짐에 따라 재난 은 불확실(uncertainty)하게 되고 상호 연계작용(interaction) 할 수 있으므로 단순 지식만으로 대비하기 어려운 실정이 다. 즉, 언제 어디서 일어날지 모르는 상황에 더해 재난 리스크가 상호 연계된 복합재난으로 확대될 경우를 대비 할 필요가 있다. 실천공동체에서의 방재교육은 지식이 일방적으로 전달되어 일회성에 그칠 수 있는 전문가·일 반인 구도의 교육방식에서 벗어나, 모든 사람이 공동체적 인 참여를 통해 지식이 점차 확대되고 재생산되어 재난 대비를 위한 형식지 및 암묵지를 바탕으로 한 재난대비 상상력 및 적응력이 축적되는 것을 의미한다. 나아가 이러 한 과정을 통해 방재를 위한 지속성을 갖추게 되는 것을 뜻한다(Yamori, 2010).

\section{3. 방재교육을 위한 향약의 적용}

\section{1 실천공동체로서의 향약}

우리의 전통향약은 상호이익 도모를 위해 규약을 정하고 결사체를 이루었던 우리나라의 실천공동체의 원형이라 할 수 있다(Ju et al., 2012). 향약은 인간은 사회 속에서 사람다운 마음(仁)과 태도(禮)를 가지고 관계해야 하며,6) 사회생활을 유지하고 지속하는 것은 협업(分)과 도덕성(義)7)이라는 유가 사상을 바탕으로 향촌(지역사회)에 거주하는 향민(주민)간 의 화목이라는 공공선(해당 주제)을 추구하기 위해서 상호 존중을 바탕으로 만들어진 지역사회 협력의 규약이다(Kwak, 1995; Woo, 2011; Choi, 2002; Kim, 2013).

향약을 조선의 현실에 맞게 반영하고 정립하는데 큰 영향 을 미친 인물로는 율곡 이이가 대표적이다.8) 율곡은 지역의

6) 춘추좌씨전(春秋左氏傳)에 따르면 공경은 예의 수레이다. 공경하지 않으면 예는 실행되지 않는다(敬, 禮之舆也. 不敬則禮不行).

7) 맹자(孟子)에 따르면 '논밭에서 우물을 함께 쓰는 백성들이, 집을 나가 고 들어감에 서로 우애하고, 지키고 망보는데 서로 도우며, 병이 났을 때 서로 도우면, 친하게 될 것이다(鄉田同井, 出入相友, 守望相助, 疾 病相扶持, 則百姓親睦)' 라고 하었다.

8) 율곡이 향약에 대해서 시행을 정지해야 한다는 입장에 있었던 이유는 당시 조선사회의 빈곤상황부터 해결한 후 시행하자는 관점에서 출발 하였기 때문이다. 따라서 향약 자체를 반대한 것으로 볼 수는 없다 (Oh, 1989). 
행정가로서 당시 연산군의 폭정 이후에 이어지는 당파싸움 과 세금 및 토지제도의 문란 등으로 사회가 혼란했던 시기에 지역사회의 질서회복을 위해 향약을 활용하였다. 또한 향약 을 전국공통으로 보편적 도입을 한 것이 아니라 각 지역의 실정에 맞게 제정하고 시행한 것에 큰 의의가 있다. 율곡의 이러한 향약에 대한 생각이 잘 나타나 있는 것은 율곡전서의 서원향약(西原鄉約)이다(Yu, 2005).

향약이란 옛날 자치규약이다. 같은 구역에 사는 사람이 도적을 막는데 서로 돕고 병이 들었을 때 서로 구제하고 출입할 때 서로 돕는 데 목적이 있다. (중간생랙) 삼대의 다스림이 융성하고 풍속이 아름다웠던 것도 진실로 이에 연유한다.9)

Table 1은 향약과 방재교육을 비교한 것이다. 다음 절에서 는 향약을 실천공동체 교육의 세 가지 요소인 '학습자의 내면화', ‘참여를 통한 실천공동체의 형성, '정체성 형성’로 나누어 분석하고 이를 통한 방재교육의 실천전략을 구체적 으로 살펴보기로 한다.

Table 1. Comparison Between Disaster Prevention Education and Hyangyak

\begin{tabular}{|c|c|c|}
\hline & $\begin{array}{l}\text { Disaster prevention } \\
\text { education }\end{array}$ & Hyangyak \\
\hline \multirow{3}{*}{ Stakeholder } & $\begin{array}{c}\text { Central and local } \\
\text { government }\end{array}$ & $\begin{array}{l}\text { Government in the } \\
\text { Joseon Dynasty }\end{array}$ \\
\hline & $\begin{array}{c}\text { Disaster management } \\
\text { experts }\end{array}$ & Confucian scholars \\
\hline & Residents & $\begin{array}{c}\text { Residents } \\
\text { (without social status } \\
\text { discrimination) }\end{array}$ \\
\hline $\begin{array}{l}\text { Education } \\
\text { purpose }\end{array}$ & $\begin{array}{l}\text { Human resource } \\
\text { development for } \\
\text { building disaster } \\
\text { resilient community }\end{array}$ & $\begin{array}{c}\text { Human resource } \\
\text { development for } \\
\text { establishing desirable } \\
\text { confucian community }\end{array}$ \\
\hline $\begin{array}{l}\text { Public } \\
\text { interests }\end{array}$ & $\begin{array}{l}\text { Safety and security } \\
\text { of } \\
\text { community }\end{array}$ & $\begin{array}{l}\text { Harmony of } \\
\text { community }\end{array}$ \\
\hline
\end{tabular}

\section{2 학습자의 내면화(internalization) 방안:} 지역사회 구성원으로서의 주체적 자조(自助)능력 함양

해당주제에 대해 일반인(모르고 있는 사람)이 전문가 및 행정(아는 사람)에 의해 교육을 받고 체득하는 의미의 ‘학습자의 내면화 전략'은 향약에서 다음과 같은 방법으로 실천되었다.

9) 율곡전서 권 16 , 잡서 3 , 서원향약, 340 쪽에 나오는 내용으로 현대어 풀이는 $\mathrm{Yu}(2005)$ 의 논문을 인용하였다.
향약은 유가적 사회질서 확립을 바탕으로 한다. 이것의 핵심은 인간은 사회적 관계 속에서 올바른 태도와 마음가 짐을 갖고 공공선(향약에서는 지역사회의 화목)을 위해 서로 협력한다는 것이다. 이러한 사회질서 확립을 위해 유학자가 중심이 되어 향약을 지역의 실정에 맞도록 실천 함으로써 향민의 공동체 생활에 크게 기여하였다(Kwak, 1995).

율곡의 향약에서는 유학자(아는 사람)가 30세 이하의 청년 들에게 사회적 관계에서의 사람다움의 본질인 마음가짐과 태도를 다루는 소학, 효경, 동자습 등을 읽고 체득하도록 하였다. 이러한 과정은 도덕적인 규범을 지역사회 공동체의 모든 구성원이 배우고 인간의 도리라는 공공선을 공유할 수 있도록 독려한 것이다. 즉, 사회적 관계의 기본은 바람직한 마음가짐(仁)과 가정에서의 부모에 대한 효(孝)라고 규정하고 이를 향민의 공통적 관심으로 삼아 교시(㸚示)하였다(Choi, 2005). 향약에서의 공동체 윤리는 타인에 대한 강요보다 자신 의 도덕과 인격의 함양을 가장 우선시하기 때문에 실천공동 체에서 말하는 내면화(internalization)와 일맥상통한다. 즉, 향약에서 공공선이라는 해당주제에 관해 유년 및 청년층의 마음가짐과 태도의 함양을 기본으로 삼고 이를 타인에게 강조하기 이전에 우선 자신부터 실천하도록 하였다.

현재 우리나라의 방재교육은 2014년 세월호 참사를 계기 로 교육시간을 늘리고, 교과가 신설되는 등 많은 부분에서 개선되고 있다. 조기 방재교육이 장려되고 있어 방재기초지 식을 공유하는 부분은 긍정적으로 평가할 수 있다. 효율적인 방재교육을 위해서는 조기에 실시되는 것이 중요하기 때문 이다(Song et al., 2005; Lee, 2006). 그러나 4대 안전영역10)을 전반적으로 교육하고 있어 자칫 지역에 따라 더욱 주위를 기울여야 하는 재난 리스크에 소홀할 가능성도 있다(J. Choi and Choi, 2018a). 따라서 자신이 노출된 리스크를 주체적으 로 인식(awareness)할 수 있는 방재교육 방안이 마련되어야 한다. 우선 자신이 할 수 있는 일(self-efficacy)부터 시작하는 것이 중요하다고 할 수 있다(Benight, Ironson, et al., 1999; Benight, Swift, et al., 1999; Benight and Harper, 2002). 예를 들면 가정 내에서 지진의 피해를 예방하기 위해 가구를 고정한다든지 응급환자를 위한 구급대처법을 익힌다든지 긴급사태에 대비해 방재가방을 꾸려놓는다던지 주변에 대 피소를 사전에 파악해 놓거나 대피경로를 점검하는 등의 행동이 이와 같은 것이다.

즉, 향약에서처럼 자신이 속한 지역사회의 재난 리스크에 대해 공동체의 구성원으로서 보다 성실하게 관심을 갖고 나아가 공공선의 추구를 위해 솔선할 수 있는 방재교육체계 가 필요하다.

10) 생활안전, 교통안전, 신변안전, 재난안전 


\section{3 실천공동체 구축 방안: 공동체적 참여를 통한 현안의 공유 및 전파}

전문가(가르치는 사람)와 일반인(배우는 사람)을 막론하 고 참여를 통하여 공동체를 구축하는 것이 실천공동체에서 말하는 교육의 두 번째 요소이다. 이때 참여의 개념은 전문가 와 일반인이 서로 다름을 인정하고, 각자 보유한 정체성을 발휘하여 전면적으로 참여하는 것을 말한다. 이를 통해 주변 사람에게 지식을 공유하고 그것이 점차 확대되어 해당과제를 해결하기 위한 공동체가 형성된다(Lave and Wenger, 1991; Yamori, 2009).

향약에서의 공동체 윤리는 무엇보다 자신의 도덕과 인격 의 함양을 우선시한다. 이러한 마음가짐(仁)을 실현하는 근본은 자신의 부모와 자식관계의 효라고 하였다. 이는 자신 의 부모-자식에 대한 것에서 타인의 부모 - 자식으로 확대 되어 효에서 비롯된 화목과 협력이라는 공공선(해당주제)이 지역사회로 확대되어 공동체가 구축되었다(Choi, 2002).

그리고 참여의 개념을 살펴보면 율곡의 향약은 지역사회 의 모든 구성원을 향약의 참여대상으로 하였다.11) 율곡의 서원향약을 살펴보면 '양천(良賤)을 막론하고 성실하여 착 한 일을 하려는데 뜻을 둔 자'를 참여의 대상으로 하고 있다. 유학자와 향민, 양반과 천민이 서로 다르지만, 지역사회의 공공선을 위해서는 구성원 모두가 각자 정체성을 발휘해야 한다고 생각한 것이다. 즉, 지역사회의 공공선을 위해서는 모든 향민이 이해당사자이며 이들의 협동을 위해서는 신분 의 귀천이 없다고 생각한 것이다. 이는 당시의 엄격한 신분제 도에서 볼 때 획기적(innovation)이었다고 할 수 있다(Choi, 2005). 향약은 공동체에 대한 자각적 의식과 자발성을 강조 하는 유가사상을 바탕으로 하기 때문에 향약공동체의 가입 은 관(행정)으로부터의 강요가 아니라 자발적으로 하도록 하였다. 스스로가 가입 후의 공동체에 대한 의무와 책임을 수반하는 것이다. 따라서 공동체 구성원간의 상호이익을 위한 협력도 적극적이면서 자발적으로 권장되었다고 할 수 있다(Yu, 2005).

향약에서처럼 방재교육을 위한 실천공동체의 형성을 위 해서는 우선 자신이 할 수 있는 일(self-efficacy)의 이행과 함께 이를 가족 및 주변이웃과 함께 공유하는 것이 중요하다. 향약에서 말하는 것처럼 주변의 이웃과 함께 인식하고 공유 하면 관심이 증가되고 이는 자신을 둘러싼 재난 리스크를 이해하는 데 큰 도움이 된다. 또한 이러한 방식은 방재지식이 재생산되어 점차 재난에 강한 실천공동체를 구축하는데 밑거름이 될 수 있다.

특히, 율곡의 향약에서 신분을 막론하고 지역사회를 이루 는 구성원이 의사결정과정에 참여한 것처럼, 방재교육은 궁극적으로 행정과 전문가 뿐만 아니라 학생, 회사원, 고령 층, 청년층 등의 주민이 참여하여 거버넌스를 구축하고 재난

11) 주희의 증손여씨향약과 퇴계 이황의 예안향약은 사대부 지식인만을 대상으로 하였다(Choi, 2005).
에 강한 지역사회 만들기라는 공공선에 이바지 할 수 있도록 해야 한다. 이러한 방식은 지역사회의 방재계획수립에도 관여하도록 발전할 수 있다(Matsuda and Okada, 2006; Okada et al., 2013; Samaddar et al., 2015). 대다수의 주민은 지역방 재에 대해 행정 의존도가 크다. 향약에서처럼 주민이 자주적 으로 활동하며 지역공동체에서 해결을 자주적으로 도모하 고, 주민이 해결할 수 없는 사항에 대해서는 행정의 지원을 요청하는 등의 방식이 필요하다. 즉, 행정의 서비스를 통한 방재계획의 수동적 참여가 아니라 주민이 지역사회의 방재 를 위해 자주적인 역할을 도모하고 그에 대한 활동을 행정으 로부터 지원받는 것이다. 방재에 대한 오너쉽을 가지고 주체 를 행정에서 지역사회 주민으로 옮겨 방재의 활동영역에 행정 및 필요자원을 점차적으로 포함시키는 것이라 할 수 있다(C. Choi and Choi, 2018a, 2018b).

\section{4 정체성 형성 방안: 지역사회 실정반영을 위한 상호 배움}

실천공동체의 교육은 배운 지식을 내면화하고 주변이웃과 공유하여 공동체를 구축하는 것으로 그치는 것이 아니라 한 단계 더 나아가 참여하는 사람의 정체성이 변화하는 것이 다(Lave and Wenger, 1991). 이는 배우는 사람과 가르치는 사람이 각자가 가지고 있는 정체성이 변화하여 배우는 사람 은 가르치고, 가르치는 사람은 배우게 되는 과정을 말한다.

향약에서도 실천공동체가 말하는 정체성의 형성이 나타난 다. 율곡은 향촌(지역사회)의 실정에 맞는 향약을 작성하기 위해 자신도 향토의 실정을 파악하였지만, 그보다 향민(일반 인)의 의견을 수렴하였다. 즉, 율곡은 서원향약과 파주향약을 작성할 때 중국에서 전해진 규약인 주자증손여씨 향약(朱子 增損呂氏師約) 등만을 의존하지 않고, 조선의 실정 그리고 부임한 향촌의 실정에 맞게 향민의 의견을 듣고 반영하였고 또 고장의 부로들과 상의하였다. 이런 과정을 통해 앞서 만들어진 향약의 번잡한 부분은 줄여지고 필요한 부분은 보강되여 새로운 향약이 집필 및 시행되었다(Yoon, 2002), 즉, 전문가인 율곡이 향민들에게 지역의 실태와 공공선을 위해 어떻게 해야하는 가를 배운 과정이라고 풀이할 수 있다.

이는 방재교육에도 큰 의의를 갖는다. 지역의 방재대책을 마련할 때 어느 곳에나 통용되는 일반해(universal solution) 보다는 지역마다 사회적으로 실현 가능한 해결책(socially viable solution)이 필요하다(Okada, 2006; Shiroshita, 2012). 이러한 사회적으로 실현가능한 해결책을 마련하기 위해 전문가가 지역주민의 현안(concern)에서 배우고, 지역주민 은 자신이 전문가에게 배운 내용을 타인에게 가르쳐주는 것은 실천공동체에서 말하는 궁극적인 방재교육에 부합한 다고 할 수 있다.

향약에서처럼 우선 행정을 포함한 전문가가 방재교육에 서 실시하기에 앞서 해당지역이 당면한 재난 리스크가 무엇 인지 파악하고 지역실정에 맞도록 방재교육을 실시하는 
Table 2. Hyangyak Based on Communities of Practice for Disaster Prevention Education and its Implications

\begin{tabular}{|c|c|c|}
\hline $\begin{array}{l}\text { Education Points for } \\
\text { Community of Practice }\end{array}$ & Solving method using Hangyak & Implications \\
\hline Internalization of learner & $\begin{array}{l}\text { - Process to prioritize one's own morality and } \\
\text { character building for community ethics rather } \\
\text { than forcing those characteristics on others }\end{array}$ & $\begin{array}{l}\text { - Development of autonomous self-help spirit as } \\
\text { community members }\end{array}$ \\
\hline $\begin{array}{l}\text { Community of Practice } \\
\text { construction }\end{array}$ & $\begin{array}{l}\text { - To practice one's own community ethics with } \\
\text { family and neighbors and to disseminate them to } \\
\text { the community } \\
\text { - To encourage participation without social status } \\
\text { discrimination and without coercion from the } \\
\text { government }\end{array}$ & $\begin{array}{l}\text { - Voluntary participation and dissemination of } \\
\text { community concerns }\end{array}$ \\
\hline Identity formation & $\begin{array}{l}\text { To reflect residents' opinions and concerns and } \\
\text { to discuss them with the village elders in order } \\
\text { to develop Hangyak }\end{array}$ & - Co-learning to reflect community circumstances \\
\hline
\end{tabular}

것이 가장 우선되어야 할 전략이라 할 수 있다. 빈번하게 지적되는 예로 방재교육을 실시할 때 지역이 당면한 과제가 아닌 재난 리스크를 논한다던가 도시에 존재하지 않는 인프 라를 대상으로 지역의 사회적 취약성(social vulnerability)을 논하여 방재에 대한 관심이 저하되는 사례가 있다. 또한 초등학교에서 방재전문용어로 이루어진 이론적 방재교육을 실시하는 것이나 재난약자와 고령층에게 활발한 신체활동 이 수반되어야 하는 대피훈련을 가르치는 것 등이 이에 해당한다. 이는 방재교육에 참여한 학습자의 관심을 유도하 기 어렵다.

지역의 실정에 맞는 방재교육을 위하여 정체성이 변화된 과정-서로 배우는 과정-은 일반인의 입장에서 볼 때 방재대책 마련을 위한 사전의 정보공유와, 결정과정에서의 권리의 공 유, 결과에 대한 책임의 공유 등 세 가지 민주적 절차를 밟은 것이라고 볼 수 있다(Lee, 2012). 나아가서 방재지식의 일방적 인 수렴이 아닌, 학습자가 가르치는 상황으로 정체성이 변화 하는 과정은, 개개인의 방재의식이 향상되었다는 점에서 효고 행동강령 2005-201512)에서 말하는 재난에 강한 지역사회 만들기를 위한 재난 대응능력 개발(capacity building)과 밀접 한 관련이 있다고 할 수 있다(UNISDR, 2005).

\section{4. 결 론}

이상으로 효과적인 방재교육의 실천방안을 검토하기 위 해 실천공동체의 개념을 살펴보고 그것이 방재교육에 있어 중요한 이유를 분석하였다. 그리고 우리의 전통향약을 실천 공동체의 역사적 사례로 파악하여 여기서 실천된 참여 및 운영방법 등을 토대로 방재교육에 적용할 수 있는 유의미한 방안을 모색하였다.

사회가 복잡해지고 재난발생이 더욱 불확실하게 됨에 따라 앞으로는 단순한 방재지식 및 기술의 전달이라는 일방 적 방재교육 방식에서 벗어나 실천공동체의 관점을 통해

12) Hyogo Framework for Action 2005-2015: Building the Resilience of Nations and Communities to Disasters
방재에 대한 주체성과 응용력 그리고 지속성을 갖추는 교육 이 필요하다. 이러한 실천공동체는 단지 서양학자가 주장한 학술적인 이론이 아니라 향약이라는 공동체 규약을 통해 이미 우리의 역사와 문화속에서 실천되고 구성되었던 개념 임을 알 수 있었으며, 이를 방재교육에 적용하는 것은 우리에 게 보다 친화적인 시도라고 할 수 있다.

전 장에서 논의하였듯이 향약의 활용에 따른 방재교육의 개선점은 요약하면 '지역사회 구성원으로써의 주체적 자조 능력 함양', ‘공동체적 참여를 통한 현안의 공유 및 전파' 그리고 '지역사회 실정반영을 위한 상호 배움' 등으로 정리 할 수 있다. 즉, 앞으로의 방재교육은 공동체적 대응을 위한 모색이 필요하다고 할 수 있다.

방재교육에서 전문가가 일방적으로 방재지식을 전달하 는 것에 그친다면 대규모 재난에서의 응용이 어려울 수 있다. 방재지식으로 습득할 수 있는 재난대처 방안은 확률적 으로 예측이 가능한 수준의 재난이다. 주체적인 재난대처 판단과 주변과의 협력이 요구되는 대규모 재난에서는 활용 할 수 있는 범위가 제한되어 있다. 따라서 본 연구에서 지적한 것처럼, 지식을 재생산하여 공동체를 구축하거나 배우는 입장에서 가르치는 입장이 되어 행정 및 전문가가 철수한 이후에도 대응할 수 있는 지속성과 상상력을 함양하고 실천 해야 할 것이다.

주민 스스로의 주체적 활동과 지역사회의 협력, 그리고 행정의 지원이 갖추어 질 때 효과적인 방재대처를 할 수 있으며, 방재교육은 위 세 가지를 보다 효율적으로 적용할 수 있는 사람으로 양성하기 위한 수단이라고 할 수 있다. 향약에서 살펴본 것처럼 앞으로의 방재교육은 행정의 지원 이 기반이 된 후에 주민이 주체적인 행동을 도모하는 것이 아니라 주민이 공동체를 기반으로 자발적으로 방재관련 활동을 도모하고 거기에 부족한 사항을 행정에게 요구하는 이른바 방재에 대한 오너쉽을 발휘할 수 있도록 도모하는 것이 바람직하다. 이러한 오너쉽을 갖게 된다면 세대에 걸쳐 언제 발생할지 모르는 대규모 재난 대비에 적합한 지속성과 상상력을 발휘하는데 큰 도움이 될 것으로 생각한다. 따라서 
앞으로의 방재교육은 학습자의 내면화, 실천공동체의 형성, 정체성의 변용이라는 실천공동체의 세 가지 교육요소가 선순환되는 과정을 목표로 해야 할 것이다. 이러한 목표를 달성하기 위해서 우리의 선조들이 앞서 생각한 전통향약의 방안은 보다 나은 방재교육을 구성하는데 시사하는 바가 크다고 하겠다.

\section{감사의 글}

본 연구는 2017년 정부(교육부)의 재원으로 한국연구재단 의 지원을 받아 수행되었습니다(NRF-2017S1A3A2066149).

\section{References}

Atsumi, T. (2006). Design disaster prevention education. Journal of Natural Disaster Science, Vol. 24, No. 4, pp. 350-356. Retrieved from http://hdl.handle.net/1 1094/3298

Bajek, R., Matsuda, Y., and Okada, N. (2008). Japan's Jishu-bosai-soshiki community activities: Analysis of its role in participatory community disaster risk management. Natural Hazards, Vol. 44, No. 2, pp. 281-292.

Benight, C., Ironson, G., Klebe, K., Carver, C.S., Wynings, C., Burnett, K., Greenwood, D., et al. (1999). Conservation of resources and coping self-efficacy predicting distress following a natural disaster: A causal model analysis where the environment meets the mind. Anxiety, Stress, \& Coping, Vol. 12, No. 2, pp. 107-126. doi:10.1080/10615809908248325

Benight, C., Swift, E., Sanger, J., Smith, A., and Zeppelin, D. (1999). Coping self-efficacy as a mediator of distress following a natural disaster. J. Appl. Soc. Psychol., Vol. 29, No. 12, pp. 2443-2464. doi: 10.1111/j.1559-1816.1999.tb00120.x

Benight, C., and Harper, M. (2002). Coping self-efficacy perceptions as a mediator between acute stress response and long-term distress following natural disasters. J. Trauma. Stress, Vol. 15, No. 3, pp. 177-186. doi: 10.1023/A:1015295025950

Chen, L.C., Liu, Y.C., and Chan, K.C. (2006). Integrated community-based disaster management program in Taiwan: A case study of Shang-An village. Natural Hazards, Vol. 37, pp. 209-223. doi:10.1007/s11069-0 05-4669-5

Choi, C., and Choi, J. (2018a). Development and distribution of risk governance framework in terms of socially viable solutions. Journal of Asian Finance, Economics and Business, Vol. 5, No. 3, pp. 185-193.

Choi, C., and Choi, J. (2018b). Distribution and application of community-based disaster risk information: Lessons from Shiga prefecture in Japan. Journal of Distribution Science, Vol. 16, No. 6, pp. 15-23.

Choi, E. (2010). Exploring on the development process and influencing factor of communities of practice (CoPs) initiated by organization in the public sector: Case study of a provincial office of education. Ph.D. dissertation, Korea University.

Choi, J., and Choi, C. (2018). The development of earthquake disaster prevention education for schools and its application. J. Korean Soc. Hazard Mitig., Vol. 18, No. 4, pp. 57-64.

Choi, J., and Yoon, D. (2017). A study on the international cooperation strategies of Korea for disaster prevention through the analysis of Japan's official development assistance (ODA) cases. J. Korean Soc. Hazard Mitig., Vol. 17, No. 5, pp. 67-74.

Choi, M. (2002). A focus on communitarianism: A new prospect of Yulgok Hyangyak. Journal of Eastern Philosophy, Vol. 30, pp. 27-52.

Choi, Y. (2005). Political participation of confucian scholar and ideology of local self-government in Joseon Dynasty. Journal of Korean Political and Diplomatic History, Vol. 27, No. 1, pp. 5-34.

Iwahori, T., Miyamoto. T., Yamori, K., and Shiroshita, H. (2015). Practice of disaster education based on legitimate peripheral participation theory. Journal of Japan Society for Natural Disaster Science, Vol. 34, No. 2, pp. 113-128. Retrieved from https://www.jsnds.org/ ssk/ssk_34_2_113.pdf

Jeon, J. (2012). A study on the meanings and implications for moral education of communities of practice. Korean Journal of Elementary Education, Vol.23, No.1, pp. 75-93.

Ju, O., Kim, N., and Ki, Y. (2012). A study on process of local indigenous meetings into a community of practice(CoP): focusing on Jangheung school. Journal of Local Government Studies, Vol. 24, No. 4, pp. 161-186. (in Korean) Retrieved from http://www.riss. kr/link?id=A99722249

Kim, D. (2003). Building a community of practice in the university for fostering web-based instructional designers' expertise: The case study of design studio in the university of Georgia. Journal of Educational 
Technology, Vol. 19, No. 3, pp. 199-229.

Kim, H. (2013). A study on the possibility and limits of community making at the principles and operations in Go-hyun Hyang-yak. The Korea Spatial Planning Review, Vol. 79, pp. 77-89.

Kim, I. (2009). Hyangyak, Invitation to Governance. Proceedings of 2009 Winter Conference, The Korean Association for Public Administration, pp. 840-853.

Kim, Y. and Lim, H. (2010) A qualitative case study on the development of network as communities of practice in welfare network of S district in Seoul. Korea. Korean Journal of Social Welfare, Vol. 62, No. 3, pp. 299-321.

Kwak, H. (1995) A on the significance and the function of welfare administration of Hyangyak in Chosun dynasty. Korean Journal of Public Administration, Vol. 41, No. 1, pp. 23-45.

Lave, J., and Wenger, E. (1991). Situated learning: Legitimate peripberal partcipation. NY: Cambridge University Press.

Lee, H. (2006). e-Learning system for disaster prevention \& emergency management training program in Japan. Proceedings of 2006 Autumn Conference, The Korea Contents Association, Vol. 4, No. 2, pp.372-376.

Lee, J. (2012). Crisis management. Seoul: Daeyoung Publication.

Matsuda, Y., and Okada, N. (2006). Community diagnosis for sustainable disaster preparedness. Journal of Natural Disaster Science, Vol. 28, No. 1, pp. 25-33.

Na, J.I., Okada, N., and Fang, L. (2009). A collaborative action development approach to improving community disaster reduction using the Yonmenkaigi System. Journal of Natural Disaster Science, Vol. 30, pp. 57-69.

Oh, H. (1989). A Study on Yulgok's Thought in Hyang Yak and Sachang GgeYakSok. Chung-Ang Historical Review, Vol. 6, pp. 99-132.

Okada, N. (2006). Perspective on integrated disaster risk management. In Y. Hagihara, N. Okada, and H. Tatano (Eds.), Introduction to Integrated Disaster Risk Management (pp. 5-9). Kyoto, Janpan: Kyoto University Academic Press.

Okada, N., Na, J.I., Fang, L., and Teratani, A. (2013). The Yonmenkaigi System Method: An implementation oriented group decision support approach. Group Decision and Negotiation, Vol. 22, No. 1, pp. 53-67.

Park, T. (2014). The study of alteration progress about continuity and rupture of Korean's cultural meme. The Journal of Humanities, Humanities Research Institute, Kyungsung University, Vol. 34, pp. 307-341.

Renn, O. (2008). Risk governance: Coping with uncertainty in a complex world. London: Earthscan.

Saint-Onge, H., and Wallace, D. (2003). Leveraging communities of practice for strategy advantage. NY: Butterworth-Heinemann.

Samaddar, S., Choi, J.H., Misra, B.A., and Tatano, H. (2015). Insights on social learning and collaborative action plan development for disaster risk reduction: Practicing Yonmenkaigi System Method (YSM) in flood-prone Mumbai. Natural Hazards, Vol. 75, No. 2, pp. 1531-1554. doi:10.1007/s11069-014-1380-4

Shiroshita, H. (2012) Disaster education after the Great East Japan Earthquake. Safety Science Review 2011, Vol. 2, pp. 44-45. (in Japanese)

Song, M.K., Lee, J.E., Moon, S.Y., Yang, S.J., and Kim, S.J. (2005). Contents analysis of textbook related to safety education in elementary school. Journal of Korean Academy of Community Health Nursing, Vol. 16, No. 2, pp. 205-220.

Sun, Y., Yamori, K., Kondo, S., and Tanisawa, R. (2012). Analysis of community disaster management based on the theory of communities of practice: A case study in Okitsu community. Journal of Japan Society for Natural Disaster Science, Vol. 31, No. 3, pp. 217-232.

The Academy of Korean Studies. (2018). Encyclopedia of Korean Culture.

UNISDR. (2005). Hyogo Framework for Action 2005-2015: Building the Resilience of Nations and Communities to Disasters.

UNISDR. (2015). Sendai Framework for Disaster Risk Reduction 2015-2030.

Wenger, E. (1998). Communities of practice: Learning meaning, and identity. New York: Cambridge University Press.

Wenger, E., and Snyder, W. (2000). Communities of practice: The organizational frontier. Harvard Business Review, Vol. 78, pp. 139-145.

Wenger, E., McDermott, R.A., and Snyder, W. (2002). Cultivating communities of practice: A guide to managing knowledge. Boston, MA: Harvard Business Press.

Woo, H. (2011). The characteristics of county magistratemade local autonomy system("hyang-yak") in later 
Chosun dynasty period in comparison with Independent middle period ones. Journal of Association for Korean Public Administration History, Vol. 29, pp. 203-219.

Yamori, K. 2009. Action research on disaster reduction education: Building a "Community of Practice" through a gaming approach. Journal of Natural Disaster Science, Vol. 30, No. 2, pp. 83-96.

Yamori, K. (2010). Disaster education and its future perspectives in Japan following the Great HanshinAwaji Earthquake. Journal of Japan Society for Natural Disaster Science, Vol. 29, No. 3, pp. 291-302.

Yamori, K. (2011). The roles and tasks of implementation science on disaster prevention and reduction knowledge and technology: From efficient application to collaborative generation. Journal of Integrated
Disaster Risk Management, Vol. 1, No. 1, pp. 48-58. Yamori, K., and Kao, Y. (2007). A gaming approach to disaster preparedness learning: An action research at a senior high school. The Japanese Journal of Experimental Social Psychology, Vol. 47, No. 1, pp. $13-25$.

Yoon, S. (2002). Ideal inclination of Yulgok Hyangyak. Journal of Yulgok-Studies, Vol.5, pp. 23-56.

$\mathrm{Yu}, \mathrm{S}$. (2005). A study on the social thought appeared on Yulgok Hyangak. Philosophical Investigation, Vol. 18, pp. 5-28.

\begin{tabular}{l|l} 
Received & August 29, 2018 \\
Revised & August 31, 2018 \\
Accepted & September 6, 2018
\end{tabular}

